\title{
Katia BUISSON, Laïcité et prison
}

Lyon, Éd. Chronique sociale, 2019

\section{Philippe Ségur}

\section{(2) OpenEdition}

\section{Journals}

Édition électronique

URL : https://journals.openedition.org/rdr/1328

DOI : $10.4000 /$ rdr.1328

ISSN : 2534-7462

\section{Éditeur}

Presses universitaires de Strasbourg

\section{Édition imprimée}

Date de publication : 16 novembre 2020

Pagination : 210-212

ISBN : 979-10-344-0073-7

ISSN : 2493-8637

Référence électronique

Philippe Ségur, «Katia Buısson, Laïcité et prison », Revue du droit des religions [En ligne], 10 | 2020, mis en ligne le 16 novembre 2020, consulté le 03 mai 2022. URL : http://journals.openedition.org/rdr/1328 ; DOI : https://doi.org/10.4000/rdr.1328

Ce document a été généré automatiquement le 3 mai 2022.

\section{(c) (1) (8)}

La revue du droit des religions est mise à disposition selon les termes de la Creative Commons Attribution - Pas d'Utilisation Commerciale 4.0 International - CC BY-NC 4.0. 


\title{
Katia BUISSON, Laïcité et prison
}

\author{
Lyon, Éd. Chronique sociale, 2019
}

\section{Philippe Ségur}

\section{RÉFÉRENCE}

Katia BuISSON, Laïcité et prison, Lyon, Éd. Chronique sociale, 2019 (Comprendre la société), 148 p.

1 Ce petit ouvrage didactique et bien conçu se propose d'étudier les conditions dans lesquelles sont garanties la laïcité et la liberté de pensée, de conscience et de religion en prison. Véritable révélateur, la laïcité « grossit et décuple certains travers de notre société »(p.11). L'auteure rappelle, en effet, que la lutte contre la radicalisation islamiste exprime dans l'univers carcéral toutes ses contradictions : comme l'a prouvé l'échec de la création des unités dédiées par la loi du 3 juin 2016, la stigmatisation du « radicalisé » ou " en voie de l'être » conduit à sa ségrégation, laquelle renforce, quand elle ne la crée pas, son identité d'insurgé. Une réponse plus adéquate a consisté à créer des aumôneries musulmanes et à mieux les encadrer. Le décret du 3 mai 2017 relatif aux aumôniers militaires, hospitaliers et pénitentiaires prévoit désormais pour ceux-ci une formation civile et civique obligatoire délivrée par un établissement d'enseignement supérieur public ou privé, formation qui conditionne leur éventuelle rémunération sur fonds publics. Cette intervention étatique dans l'aumônerie carcérale, prévue par la loi de 1905, a été accrue à l'initiative du gouvernement Valls après les attentats du 7-9 janvier 2015.

2 Par ailleurs, la laïcité impose à l'administration pénitentiaire à la fois une obligation de neutralité pour ses personnels, quel que soit leur statut, et le devoir de rendre possible le libre exercice des cultes. Celui-ci suppose droit à l'information en matière religieuse, droit à la visite d'un ministre du culte en cellule, droit d'assister à des offices ou des réunions cultuelles, droit de ne pas être dérangé par une fouille le temps de la prière, droit aux ouvrages nécessaires à la vie spirituelle, droit de s'entretenir avec un aumônier, etc. (p. 66 et s.). À ce titre, les aumôniers sont les seuls intervenants 
extérieurs à pouvoir disposer des clefs des cellules et introduire des objets nécessaires à la pratique cultuelle.

3 L'exercice de ces droits se heurte néanmoins à l'insuffisance des moyens, en particulier pour les lieux de culte qui se réduisent souvent à une chapelle dans les prisons anciennes ou à un gymnase. En matière alimentaire, si, depuis 2009, le ramadan implique un aménagement uniforme des horaires de restauration dans toutes les prisons pour les détenus qui en font la demande, la fourniture d'une nourriture halal ne saurait être envisagée selon le juge administratif qui avance des motifs économiques (CE, 16 juill. 2014, n ${ }^{\circ}$ 377145) alors qu'un argument tiré de la laïcité était plutôt attendu : comme le rappelle Katia Buisson, « l'État neutre en matière cultuelle ne peut pas financer de repas cultuels » (p. 88). Le respect des prescriptions alimentaires est donc laissé à l'initiative et aux frais du détenu par le système du «cantinage ", ce dernier lui permettant d'acheter de la nourriture à caractère confessionnel grâce à son pécule.

4 La liberté religieuse en prison est également limitée par cela même qui justifie depuis vingt ans sa plus grande prise en compte: le prosélytisme. Si la manifestation de la croyance fait partie intégrante de la liberté religieuse, il y a dans le zèle déployé pour susciter la conversion une zone grise voisine de l'endoctrinement, rendu plus facile dans un milieu fermé et dont l'État ne peut se désintéresser lorsque les doctrines présentent un danger social manifeste, ce qui est le cas de l'idéologie islamiste. C'est pourquoi, en particulier, le port des vêtements religieux est interdit en prison dans les lieux à usage collectif non confessionnels, tandis que celui des signes religieux ostensibles est lui-même prohibé.

5 Au fil du texte, l'auteure met en évidence les ambiguïtés de la politique pénitentiaire en matière religieuse. Au-delà de l'humanisation affichée, elle rappelle que les activités confessionnelles remplissent, à moindres coûts, une fonction d'occupation du temps et des énergies inemployées et contribuent par là même à la gestion et à la maîtrise des détenus. Outre d'éventuelles vertus pacificatrices, elles visent aussi à la réformation des condamnés comme étape utile à leur réinsertion dont les aumôniers sont conçus par le Code de procédure pénale comme des acteurs essentiels. Cependant la professionnalisation de ces derniers - réclamée en particulier par les musulmans, catholiques et protestants demeurant attachés à la conception bénévole de leur fonction (p. 113) - ne laisse d'interroger. Ils se voient, en effet, invités à participer à la surveillance pénitentiaire par le signalement des indices de radicalisation, notamment au sein des commissions pluridisciplinaires uniques auxquelles la circulaire du 18 juin 2012 et la note du 16 juillet 2014 leur permettent de siéger. C'est donc à bon droit, en définitive, que Katia Buisson voit dans la laïcité en milieu carcéral «à la fois un outil de contrôle et de respect des cultes ». 


\section{AUTEURS}

PHILIPPE SÉGUR

Professeur de droit public, Université de Perpignan Via Domitia, Centre du droit économique et du développement (CDED) 